\title{
Effect of Different Insulin Therapies on Obstetric-Fetal Outcomes
}

\author{
Cristina López-Tinoco ${ }^{1 *}$, José Luis Jiménez-Blázquez ${ }^{2}$, Laura Larrán-Escandón ${ }^{3}$, \\ María del Mar Roca-Rodríguez ${ }^{3}$, Fernando Bugatto ${ }^{4}$ Manuel Aguilar-Diosdado ${ }^{1}$
}

To evaluate the effectiveness of the different insulin therapies on obstetrics-fetal outcomes in women with pregestational diabetes mellitus. We enrolled 147 pregnant women with pre-existing type 1 or 2 diabetes mellitus. Clinical and biochemical parameters were analysed in relation to obstetric and fetal outcomes. $14.2 \%$ received treatment with Neutral Protamine Hagedorn insulin and short-acting insulin analogues; $19 \%$ with premixed human insulin; $40.1 \%$ with insulin glargine and lispro, $6.2 \%$ with detemir and aspart and $20 \%$ with continuous subcutaneous insulin infusion. All 5 types of treatment achieved a reduction of the mean $\mathrm{HbA1c}$ during pregnancy $(\mathrm{p}=0.01)$. Pre-pregnancy care was carried out for $48 \%$ of patients. We found no statistically significant differences between the different insulin therapies and the obstetric-fetal outcomes. In conclusión, the different insulin therapies used in patients with pregestational diabetes mellitus does not seem to affect obstetric-fetal outcomes.

Diabetes mellitus is one of the most frequent metabolic complications of gestation and it is associated with an increased risk of maternal and fetal morbidity and mortality ${ }^{1}$. Approximately $1 \%$ of all pregnant women present pregestational diabetes mellitus (PGDM), however, this prevalence is increasing ${ }^{2}$. It is widely acknowledged that pre-pregnancy care (PPC) is beneficial for women with PGDM to minimize risks in the fetus and the mother ${ }^{3}$.

Women with PGDM present worse results than pregnant women without diabetes mellitus, with an increase in the rate of congenital malformations, preeclampsia, preterm birth, perinatal mortality, macrosomia ${ }^{4,5}$ and worsening of retinopathy and diabetic nephropathy ${ }^{6}$. Therefore, it is essential to achieve an optimum glycaemic control before and during gestation ${ }^{1}$.

Nowadays, insulin is the treatment of choice for PGDM, however, there is no clear evidence of a difference between regular human insulin and other types of insulin in gestational diabetes ${ }^{7}$. In fact, alterations in the placenta and umbilical vessels in the fetus of women with gestational diabetes treated with insulin have been seen ${ }^{8}$.

Neutral Protamine Hagedorn (NPH) insulin is recommended. Several studies support the safety and efficacy of insulin analogues in pregnancy ${ }^{9}$. The short-acting insulin analogues (lispro and aspart) are comparable in immunogenicity to rapid human insulin and they are not teratogenic. And they also achieve the objectives of postprandial control with lower risk of hypoglycaemia ${ }^{10}$. The long-acting insulin analogues (detemir and glargine) improve the fasting plasma glucose and glucose fluctuations without an increased incidence of nocturnal hypoglycaemia ${ }^{9}$ and they have not demonstrated significant adverse effects on outcomes of the pregnancy ${ }^{9,10}$. In fact, since 2012, the Food and Drug Administration (FDA) has reclassified basal insulins from category "C" to "B" and so they can be used in pregnancy?.

In women with type 1 PGDM, if adequate glycaemic control is not achieved with the use of multiple doses of insulin (MDI) in bolus-basal regimen (long-acting insulin analogues plus short-acting insulin analogues at each meal), the use of continuous subcutaneous insulin infusion (CSII) is recommended ${ }^{11}$. In women with type 2 PGDM who receive oral antidiabetic treatment, they should be treated with insulin therapy during pregnancy. Ideally, insulin therapy should be initiated during the preconception period ${ }^{1}$.

Thus, it is important to know whether the different insulin therapies used in patients with PGDM has an impact on obstetrics-fetal outcomes, and whether the establishment of therapeutic and preventive strategies can reduce them.

The aim of the present study was to evaluate the effectiveness of the different insulin therapies on obstetrics-fetal outcomes and to assess the impact on maternal metabolic outcomes in relation to the PPC.

${ }^{1}$ Department of Endocrinology, Puerta del Mar Hospital Cádiz/ Department of Medicine, University of Cádiz, Av. Ana de Viya 21 CP:11009 Cádiz/Dr. Marañón, 3 CP: 11002, Cádiz, Spain. ${ }^{2}$ Department of Medicine, University of Cádiz, Dr. Marañón, 3 CP: 11002, Cádiz, Spain. ${ }^{3}$ Department of Endocrinology, Puerta del Mar Hospital, Av. Ana de Viya 21, CP: 11009, Cádiz, Spain. 4Department of Obstetrics and Gynaecology, Puerta del Mar Hospital, Cádiz, Av. Ana de Viya 21, CP: 11009, Cádiz, Spain. *email: cristinalopeztinoco@gmail.com 


\section{Study Design}

Study population. We enrolled 147 pregnant women for this study from among subjects who were attending the Endocrinology and Pregnancy Clinic of Puerta del Mar University Hospital (Cádiz, Spain) from February 2007 until June 2017. The women included had a singleton gestation, pre-existing type 1 or $2 \mathrm{DM}$, clinical follow-up from the first trimester of gestation until delivery. The candidates who fulfilled the selection criteria were informed of the characteristics and objectives of the study before they signed specially-designed informed consent forms to participate in the study.

Study subjects included 113 women with type 1 PGDM and 34 with type 2 PGDM. Both groups of women were comparable; there was no significant difference with respect to BMI. They had the same modality of treatment from the moment of inclusion of the study until delivery, only the dosage had been modified. Patients with type 2 PGDM received insulin treatment with short-acting insulin analogues (lispro and aspart) and NPH insulin or premixed human insulin, consisting of rapid-acting and intermediate-acting insulin analogues with different fixed-ratio mixtures of insulin preparations (for example Humalog Mix 25/50 or Novomix 30/50/70), administered two or three times daily; or MDI; three injections of rapid-acting insulin analogues before their three main meals and one injection of insulin (detemir or glargine) in the morning or and in the evening (bolus basal regimen). Patients with type 1 PGDM received treatment with MDI in bolus-basal regimen or CSII; insulin infusion bolus doses of rapid-acting insulin analogues were given immediately prior to the three main meals, while the basal infusion of insulin was adjusted hour by hour, according to the glycaemic targets for fasting. All women in the continuous subcutaneous insulin infusion group started the treatment with pumps before pregnancy. Our clinic's dietician prescribed individualised nutritional therapy.

Prenatal visits were performed every week until delivery. HbAlc was assessed every 4 to 6 weeks. Each woman had an ultrasound scan once a trimester (at about 12, 20, 34 weeks), according to the Spanish guidelines for pregnancy monitoring. In addition, an ultrasound scan at 32 weeks was performed to assess fetal growth.

Maternal characteristics collected included: age at conception, prepregnancy body mass index (BMI) and at the end of pregnancy, weight gain in pregnancy, duration of diabetes and microvascular complications at conception (such as retinopathy, nephropathy, neuropathy), preconception care or not. Maternal metabolic data collected were: prepregnancy HbAlc, enrolment and at the end of pregnancy, insulin requirements at the beginning and end of pregnancy. Maternal outcomes included progression of microvascular complications (retinography and albumin/creatinine ratio were performed in each trimester of pregnancy), rate of non-elective Caesarean section, elective Caesarean section, vaginal delivery, abortion and fetal death.

Fetal outcomes included: abdominal circumference of the fetus measured by ultrasound scan at week 32 of pregnancy, gestational age at birth, birth weight, newborn weight percentile, rate of preterm birth (before 37 weeks), and macrosomia and APGAR score at 5 minutes after birth.

All biochemical parameters were analysed at the clinical laboratory of our hospital. Glucose was determined in venous blood using the biochemical system Modular DPD (Roche Diagnostics, Switzerland). HbA1c was measured in the Cobas Integra 700 autoanalyser (Roche Diagnostics, Switzerland) using an immunoturbidimetric method for completely haemolysed, anti-coagulated blood. The albumin/creatinine ratio was determined using an immunoturbidimetric test in the Cobas Integra 700 system (Roche Diagnostics, Switzerland).

Ethical approval. The study protocol was approved by the ethical committee of the University Hospital Puerta del Mar and followed the guidelines of the Helsinki protocol.

Statistical analysis. Descriptive statistics included mean, median, standard deviation and ranges for quantitative variables, and percentages for qualitative variables. Associations between categorical variables-of-interest and their dependent and independent variables were determined by the Mantel-Henszel $\chi^{2}$ test with the Yates correction, or the Fisher test if the variable contained $<5$ measurements. Parametric variables were compared using the Student $t$-test, and one-way analysis of variance (ANOVA). We used the Bonferone test, if the results were statistically significant. Non-parametric variables were evaluated with the Mann-Whitney test. Correlations between variables were evaluated using Spearman's rank correlation coefficient. A level of $\mathrm{p}<0.05$ was accepted as being statistically significant. Statistical analyses were with the Statistical Package for Social Sciences (SPSS 21.0 for Windows).

\section{Results}

Demographic, clinical and laboratory variables of the studied population are summarised in Table 1.

There were 5 types of insulin therapy; $14.2 \%$ received treatment with NPH insulin and short-acting insulin analogues; $19 \%$ with premixed human insulin; $40.1 \%$ with insulin glargine and lispro, $6.2 \%$ with detemir and aspart and $20.5 \%$ with continuous subcutaneous insulin infusion.

Ten women $(7,3 \%)$ had miscarriages. Nine were type 1 PGDM; all of them had 10 or more years duration of diabetes and poor metabolic control prior to gestation, with HbA1c of $8 \%$. Most of them were treated with glargine and lispro except for one who was treated with NPH insulin and lispro. Only one patient with type 2 PGDM had a pre-pregnancy HbA1c of $12 \%$ and was treated with premix insulin. Five women (3.6\%) had fetal death. Three were type 1 PGDM, one of them had twenty years duration of diabetes, a pre-pregnancy HbA1c of $10 \%$ and mean $\mathrm{HbAlc}$ of $8.67 \%$, and was treated with continuous subcutaneous insulin infusion. The other two fetal deaths had a mean $\mathrm{HbAlc}$ of $7.53 \%$ and were treated with glargine and lispro. A fetal brain malformation was observed in one of them. In another the fetal death was due to the development in the mother of a diabetic ketoacidosis and in the last case it was not possible to identify the cause of fetal death. The other patients with type 2 PGDM had 3 years duration of diabetes, a pre-pregnancy HbAlc of $8 \%$ and mean HbAlc of $7 \%$ and were treated with NPH insulin and lispro. One fetal death was due to multiple anomalies and the other was unexplained. 


\begin{tabular}{|c|c|c|c|}
\hline & Type 1 PGDM & Type 2 PGDM & $\mathbf{p}$ \\
\hline Maternal age; years & $30.3+I-4.9$ & $31.2+/-4.7$ & 0.3 \\
\hline Duration of diabetes; years & $16.1+/-6.6$ & $3.9+/-2.1$ & 0.001 \\
\hline Pre-pregnancy care; $\mathrm{N}(\%)$ & $40(35 \%)$ & $9(26 \%)$ & 0.01 \\
\hline \multicolumn{4}{|l|}{ Micro-vascular complications at conception; } \\
\hline Retinopathy; N(\%) & $41(40 \%)$ & $2(6 \%)$ & 0.001 \\
\hline Nephropathy; N\% & $21(18 \%)$ & 0 & 0.05 \\
\hline Pre-pregnancy body mass index (BMI); kg/m² & $24.3+I-2.8$ & $25.7+I-3.6$ & 0.06 \\
\hline BMI at the end of pregnancy; $\mathrm{kg} / \mathrm{m}^{2}$ & $30.1+/-2.6$ & $30.4+/-2.7$ & 0.6 \\
\hline Weight gain in pregnancy; $\mathrm{Kg}$ & $3.9+/-1.3$ & $4.6+/-1.2$ & 0.09 \\
\hline Pre-pregnancy HbAlc; \% & $7.6+/-1.4$ & $7.0+/-1.6$ & 0.08 \\
\hline Mean HbAlc in pregnancy; \% & $6.7+/-1.0$ & $6.1+/-0.8$ & 0.05 \\
\hline Insulin requirements at the beginning of pregnancy; $\mathrm{UI} / \mathrm{Kg}$ & $0.7+/-0.2$ & $0.4+/-0.2$ & 0.01 \\
\hline Insulin requirements at the end of pregnancy; $\mathrm{UI} / \mathrm{Kg}$ & $0.8+/-0.2$ & $0.6+/-0.2$ & 0.01 \\
\hline
\end{tabular}

Table 1. Demographic, clinical and laboratory variables in type 1 PGDM and type 2 PGDM. Values are given as mean $+/-$ SD or number of subjects $(n)$ with percentage in parenthesis.

\begin{tabular}{|l|l|l|}
\hline Obstetric and fetal outcomes & $\begin{array}{l}\text { Pre-pregnancy } \\
\text { HbAlc }\end{array}$ & $\begin{array}{l}\text { Mean HbAlc in } \\
\text { pregnancy }\end{array}$ \\
\hline $\begin{array}{l}\text { Fetal abdominal circumference by } \\
\text { ultrasound scan at week 32 of pregnancy }\end{array}$ & $\mathrm{P}=0.5$ & $\mathrm{P}=0.4$ \\
\hline - High range $(>298 \mathrm{~mm})$ & $7.7+/-1.7$ & $6.5+/-0.8$ \\
\hline - Normal range $(<298 \mathrm{~mm})$ & $6.9+/-1.4$ & $6.4+/-0.9$ \\
\hline Birth weight & $\mathrm{P}=0.2$ & $\mathrm{P}=0.04$ \\
\hline - $<2500 \mathrm{~g}$ & $7.4+/-1.6$ & $6.2+/-0.8$ \\
\hline - 2500-3999g & $7.1+/-1.5$ & $6.3+/-0.9$ \\
\hline - >4000g & $7.8+/-1.7$ & $6.7+/-0.9$ \\
\hline Weight percentile & $\mathrm{P}=0.007$ & $\mathrm{P}=0.001$ \\
\hline - Normal weight & $6.7+/-1.6$ & $6.1+/-0.8$ \\
\hline - Macrosomia & $7.2+/-1.6$ & $6.7+/-0.9$ \\
\hline End of Pregnancy Route & $\mathrm{P}=0.01$ & $\mathrm{P}=0.001$ \\
\hline - Vaginal birth & $6.8+/-1.4$ & $6.1+/-0.7$ \\
\hline - Elective Cesarean & $7.0+/-1.5$ & $6.5+/-1.0$ \\
\hline - Non- Elective Cesarean & $7.7+/-1.6$ & $6.5+/-0.8$ \\
\hline - Miscarriage & $8.2+/-1.8$ & $7.9+/-1.9$ \\
\hline - Fetal death & $8.5+/-1.1$ & $7.5+/-0.7$ \\
\hline Gestational age at birth & $\mathrm{P}=0.01$ & $\mathrm{P}=0.001$ \\
\hline - Preterm birth & $7.8+/-1.5$ & $7.1+/-1.3$ \\
\hline - Birth to term & $7.0+/-1.6$ & $6.2+/-0.8$ \\
\hline
\end{tabular}

Table 2. Relationship between obstetric and fetal outcomes and pre-pregnancy and mean HbA1c in pregnancy.

To investigate the relationship between obstetrics and fetal outcomes and the pre-pregnancy and mean $\mathrm{HbA1c}$, we observed that birth weight, weight percentile, end of pregnancy route and gestational age at birth were significantly related to pre-pregnancy and mean HbAlc during pregnancy. All data are summarized in Table 2.

The incidence of preterm birth was higher in women with a poor periconceptional HbAlc level. The $18 \%$ refers to spontaneous preterm birth. Most of them were medically indicated preterm birth; Caesarean in $73 \%$ of the cases of which $71 \%$ were emergency Caesarean - of which two were due to the development of severe preeclampsia, one was due to diabetic ketoacidosis in the mother and seven for induced birth following fetal macrosomia.

The association of different insulin therapies in PGDM, pre-pregnancy and mean HbAlc during pregnancy is shown in Table 3 .

The relation between different insulin therapies used and the obstetric and fetal outcomes were analysed, no statistically significant differences were found (Table 4).

Forty-nine (48\%) of pregnant women scheduled the gestation. The association of PCC and obstetrics and perinatal outcomes was studied. Only the gestational age at birth was statistically significant with respect PCC (P value $=0.04$ )

With regard to progression of maternal microvascular complications during pregnancy, four patients (2.9\%) had progression of nephropathy and twenty-three (16.3\%) had progression of retinopathy. The association of different insulin therapies and progression of maternal microvascular complications were not significant (results not shown). 


\begin{tabular}{|l|l|l|}
\hline Insulin therapies & $\begin{array}{l}\text { Pre-pregnancy } \\
\text { HbAlc\% }\end{array}$ & $\begin{array}{l}\text { Mean HbA1c in } \\
\text { pregnancy\% }\end{array}$ \\
\hline a) Type 1 PGDM & \multicolumn{2}{|l|}{} \\
\hline NPH and short-acting insulin analogues & $7.8+/-1.1$ & $6.9+/-0.9^{*}$ \\
\hline Glargine and Lispro & $7.6+/-1.4$ & $6.6+/-0.7^{*}$ \\
\hline Detemir and Aspart & $8.3+/-0.7$ & $7.04+/-0.7^{*}$ \\
\hline CSII & $7.4+/-1.3$ & $6.6+/-0.8^{*}$ \\
\hline b) Type 2 PGDM & \multicolumn{2}{|l}{} \\
\hline NPH and short-acting insulin analogues & $7.8+/-1.1$ & $6.9+/-0.9^{*}$ \\
\hline Premixed human insulin & $6.2+/-1.4$ & $5.6+/-0.5^{*}$ \\
\hline Glargine and Lispro & $7.4+/-0.8$ & $6.8+/-0.3^{*}$ \\
\hline Detemir and Aspart & $7.1+/-1.1$ & $6.1+/-0.8^{*}$ \\
\hline
\end{tabular}

Table 3. Effectiveness of different insulin therapies on HbAlc levels. NPH; Neutral Protamine Hagedorn, CSII; continuous subcutaneous insulin infusion. ${ }^{*} \mathrm{p}<0.05$. NPH; Neutral Protamine Hagedorn, ${ }^{*} \mathrm{p}<0.05$.

\section{Discussion}

The goal of glycaemic control in pregnancy is to reach a value of Hab1c as close to the normal range, without hypoglycaemia ${ }^{1}$. In order to achieve this goal, in addition to complying with adequate hygienic and dietary habits, an adjustment of the insulin treatment, using the model of insulin therapy in an individualised way to the characteristics of each patient, is required ${ }^{6}$. Our patients had a mean HbAlc of $6.53+/-1.05 \%$; we observed an improvement of the metabolic control throughout the gestation, regardless of the type of insulin treatment. Our data confirm other reports ${ }^{10}$.

Observational studies show that an HbAlc greater than $1 \%$ of the normal range is associated with a higher rate of congenital anomalies and miscarriages with respect to the general population ${ }^{12}$. The rate of miscarriages in our series was $7.3 \%$. In other series with scheduled pregnancies it was $5.7 \%{ }^{13}$ and with unscheduled pregnancies from $14 \%^{3}$. As we have already mentioned, all miscarriages occurred in patients with 10 or more years of duration of DM and poor metabolic control. Results confirm other studies that have shown that poor metabolic control in early gestation, especially during embryogenesis, is related to a higher incidence of miscarriages and congenital anomalies ${ }^{14,15}$. With respect to fetal deaths, we had 3,6\%. Results confirm other studies ${ }^{12}$.

The pre-pregnancy HbA1c of our pregnant women was $7.3+/-1.58 \%$, higher levels than those recommended $^{5}$, which coincides with the fact that there were a small number of scheduled pregnancies. It is clear that obtaining pre-pregnancy optimum metabolic control is of great importance. However, only $28 \%$ of pregnant women scheduled their gestation. In other series $75 \%$ of gestations were unscheduled ${ }^{12}$. This could be attributed to the fact that in our study we also evaluated patients with type 2 PGDM, who may have had less knowledge about their disease and the impact on gestation. Pre-pregnancy glycaemic control plays a fundamental role in reducing the frequency of fetal outcomes. When we analysed the relationship between pre-pregnancy HbA1c and obstetrics and perinatal outcomes, we found weight percentile, end of pregnancy route and gestational age at birth were statistically significant. Therefore, a better pre-pregnancy metabolic control improves the incidence of preterm delivery, which is consistent with what has already been published ${ }^{16}$.

The majority of our patients with type 2 PGDM received insulin treatment with short-acting insulin analogues and NPH or premixed human insulin, while our patients with type 1 DMPG received treatment with MDI (glargine and lispro more frequently) or CSII. Currently there are many options for insulin treatment in pregnant patients. Until now the recommended treatment has been short-acting insulin analogues and $\mathrm{NPH}^{17}$. After recognizing the safety and efficacy of insulin analogues ${ }^{9}$, it is possible to treat with long-acting analogues, especially if there is a risk of nocturnal hypoglycaemia ${ }^{18,19}$. However, there are no studies that clearly demonstrate the benefits over the rest of insulin therapies and extensive clinical experience with long-acting analogues is required ${ }^{20,21}$. With respect to treatment with CSII, some studies have specifically compared treatment with MDI vs. CSII ${ }^{22,23}$. There are studies where CSII therapy was more effective in improving the mean $\mathrm{HbAlc}$ and glycaemia than MDI therapy ${ }^{23,24}$. But in more recent studies, although mean blood glucose was lower with CSII, no differences were observed with respect to $\mathrm{HbAlc}^{25}$. In our study, there were no differences with respect to metabolic control among patients treated with MDI or CSII. In a recent Cochrane review ${ }^{26}$, it was concluded that there is no evidence that show that the use of one particular form of insulin administration is better than another in pregnant women with diabetes.

Poor metabolic control during gestation is associated with a higher prevalence of macrosomia ${ }^{4}$. In our study, the lower the mean HbAlc during pregnancy, the lower the percentage of caesarean sections, macrosomia, abortions and fetal deaths. Data confirm what is described in the literature ${ }^{4,27}$.

We also analysed the insulin therapeutic modality used, with the progression of microvascular maternal complications during pregnancy. In our study we observed a progression of retinopathy of $16.3 \%$, a percentage similar to other studies that have shown a progression of diabetic retinopathy between 20 and $55 \%{ }^{28}$. However, this is not easily comparable because it would be necessary to differentiate type 1 from type $2 \mathrm{DM}$, in order to affirm a smaller progression of complications in our series. In diabetic nephropathy, there are no conclusive studies in this respect. In our patients we observed a progression of nephropathy of $2.9 \% .14 .5 \%$ had microalbuminuria and $6.9 \%$ had nephropathy before gestation. These data coincide with what has been published, with a prevalence of approximately $11 \%$ of microalbuminuria and $5 \%$ of nephropathy ${ }^{29}$. Two large studies of women with type 1 diabetes mellitus, DCCT (Diabetes Control and Complication Trial) and the PCS (EURODIAB Prospective 


\begin{tabular}{|c|c|c|c|}
\hline $\begin{array}{l}\text { Obstetrics and fetal outcomes/ } \\
\text { Insulin therapies }\end{array}$ & $\begin{array}{l}\text { Good glycaemic } \\
\text { control (Hbalc }<7 \%)\end{array}$ & $\begin{array}{l}\text { Poor glycaemic } \\
\text { control }(\text { Hbalc }>7 \%)\end{array}$ & p \\
\hline \multicolumn{4}{|l|}{ Gestational age, weeks; } \\
\hline Glargine and Lispro & $36.5+/-8.6$ & $36.1+/-2.5$ & 0.4 \\
\hline CSII & $36.3+/-2.4$ & $35.6+/-3.8$ & 0.6 \\
\hline Premixed human insulin & $38.1+/-2.2$ & $37.8+/-0.4$ & 0.7 \\
\hline Detemir and Aspart & $38+/-0.1$ & $38.1+/-1.2$ & 0.9 \\
\hline $\mathrm{NPH}$ and insulin analogue & $38.1+/-8.6$ & $36.1+/-8.6$ & 0.8 \\
\hline \multicolumn{4}{|l|}{ Macrosomia N (\%); } \\
\hline Glargine and Lispro & 0 & $1(66 \%)$ & 0.7 \\
\hline CSII & $1(25 \%)$ & $3(75 \%)$ & 0.08 \\
\hline Premixed human insulin & 0 & $1(66 \%)$ & 0.3 \\
\hline Detemir and Aspart & 0 & 0 & 0.8 \\
\hline $\mathrm{NPH}$ and insulin analogue & 0 & $1(50 \%)$ & 0.9 \\
\hline \multicolumn{4}{|c|}{ Fetal abdominal circumference by ultrasound scan at week 32 of pregnancy; $\mathbf{m m}$} \\
\hline Glargine and Lispro & $277+/-29$ & $308+/-19$ & 0.4 \\
\hline CSII & $287+/-20$ & $300+/-26$ & 0.1 \\
\hline Premixed human insulin & $254+/-76$ & $295+/-33$ & 0.09 \\
\hline Detemir and Aspart & $348+/-10$ & $352+/-26$ & 0.1 \\
\hline $\mathrm{NPH}$ and insulin analogue & $302+/-8$ & $307+/-2$ & 0.5 \\
\hline \multicolumn{4}{|l|}{ Birth weight; gr; } \\
\hline Glargine and Lispro & $3271+/-853$ & $3641+/-477$ & 0.09 \\
\hline CSII & $3045+/-953$ & $3496+/-567$ & 0.2 \\
\hline Premixed human insulin & $3149+/-436$ & $3478+/-675$ & 0.3 \\
\hline Detemir and Aspart & $3557+/-134$ & $3399+/-239$ & 0.1 \\
\hline $\mathrm{NPH}$ and insulin analogue & $3762+/-553$ & $3552+/-597$ & 0.07 \\
\hline \multicolumn{4}{|l|}{ Caesarean N(\%); } \\
\hline Glargine and Lispro & $11(42 \%)$ & $15(57 \%)$ & 0.07 \\
\hline CSII & $8(42 \%)$ & $11(56 \%)$ & 0.8 \\
\hline Premixed human insulin & $4(50 \%)$ & $4(50 \%)$ & 0.5 \\
\hline Detemir and Aspart & 0 & $2(66 \%)$ & 0.9 \\
\hline $\mathrm{NPH}$ and insulin analogue & $4(40 \%)$ & $6(60 \%)$ & 0.1 \\
\hline \multicolumn{4}{|l|}{ Non elective Caesarean N(\%); } \\
\hline Glargine and Lispro & $6(33 \%)$ & $12(66 \%)$ & 0.06 \\
\hline CSII & $5(38 \%)$ & $11(62 \%)$ & 0.09 \\
\hline Premixed human insulin & $2(40 \%)$ & $3(60 \%)$ & 0.5 \\
\hline Detemir and Aspart & 0 & 0 & \\
\hline $\mathrm{NPH}$ and insulin analogue & $3(40 \%)$ & $5(60 \%)$ & 0.08 \\
\hline
\end{tabular}

Table 4. Obstetrics and fetal outcomes and different insulin therapies used in relation to good and poor glycaemic control. Values are given as mean $+/-\mathrm{SD}$ or number of subjects $(\mathrm{n})$ with percentage in parenthesis.

Complications Trial), concluded that gestation is not a risk factor for the development of retinopathy, nephropathy or early neuropathy after correction of confounding factors such as age, duration of diabetes and $\mathrm{HbA} 1 \mathrm{c}^{28}$.

These results are limited and still inconclusive because the study compares the effectiveness of different insulin therapies in patients with PGDM and does not discriminate subcategories of PGDM (type 1 and type 2 DM). In addition well-designed randomised clinical trials are needed to draw a conclusion.

\section{Conclusion}

The different insulin therapies used in patients with PGDM does not seem to affect obstetric and fetal outcomes. Poor glycaemic control prior to and during gestation is associated with poor obstetric-fetal outcomes. Patients who have PPC have a lower HbAlc and a reduction of obstetric and fetal outcomes. Further specifically designed studies are needed to evaluate metabolic, obstetric and fetal outcomes depending on different insulin treatment used.

Received: 16 May 2018; Accepted: 1 November 2019;

Published online: 27 November 2019

\section{References}

1. Acosta, D. et al. Asistencia a la gestante con diabetes. Guía de práctica clínica actualizada en 2014. Av Diabetol. 31, 45-59 (2015).

2. Rathmann, W. \& Giani, G. Global prevalence of diabetes: estimates for the year 2000 and projections for 2030. Diabetes Care. 27, 2568-9 (2004). 
3. Mustafa, E. et al. A regional pre-pregnancy care (PPC) programme for women with type 1 and type 2 diabetes. Ir Med Jou. 105, 11-3 (2012).

4. Shannon, M. H. et al. Pregnancy snapshot: A retrospective, observational case-control study to evaluate potential effects of maternal diabetes treatment during pregnancy on macrosomia. Curr Med Res Opin. 9, 1-37 (2016).

5. Ornoy, A., Reece, E. A., Pavlinkova, G., Kappen, C. \& Miller, R. K. Effect of maternal diabetes on the embryo, fetus, and children: congenital anomalies, genetic and epigenetic changes and developmental outcomes. Birth Defects Res CEmbryo Today. 105, 53-72 (2015).

6. American Diabetes, A. Standards of Medical Care in Diabetes-2016 Abridged for Primary Care Providers. Clinical diabetes: a publication of the American Diabetes Association. Diabetes Care. 34, 3-22 (2016).

7. Brown, J., Grzeskowiak, L., Williamson, K., Downie, M. R. \& Crowther, C. A. Insulin for the treatment of women with gestational diabetes. Cochrane Database Syst Rev. 11, CD012037 (2017).

8. Subiabre, M. et al. Insulin therapy and its consequences for the mother, foetus, and newborn in gestational diabetes mellitus. Biochim Biophys Acta Mol Basis Dis. 1864, 2949-2956 (2018).

9. Toledano, Y., Hadar, E., Hod, M. Pharmacotherapy for hyperglycemia in pregnancy - The new insulins. Diabetes Res Clin Pract. S0168-8227 (18) 30582-5. Review (2018).

10. Roca-Rodríguez, M. M. et al. Diabetes pregestacional: resultados metabolicoperinatales según la terapia empleada. Prog Obstet Ginecol 53, 255-60 (2010).

11. Mello, G. et al. Continuous subcutaneous insulin infusion (CSII) versus multiple daily injections (MDI) of rapid-acting insulin analogues and detemir in type 1 diabetic (T1D) pregnant women. J Matern Fetal Neonatal Med. 28, 276-80 (2015).

12. Jovanovic L. Glycemic control in women with type 1 and type 2 diabetes mellitus during pregnancy. Uptodate (2008).

13. Shefali, A. K., Kavitha, M., Deepa, R. \& Mohan, V. Pregnancy outcomes in pre-gestational and gestational diabetic women in comparison to non-diabetic women. A prospective study in Asian Indian mothers. J Assoc Physicians India. 54, 613-8 (2006).

14. Harris, B. S. et al. Risk Factors for Birth Defects. Obs and Gynae Survey. 72, 123-35 (2017).

15. Temple, R. C., Albridge, V. J. \& Murphy, H. R. Prepregnancy care and pregnancy outcomes in women with type 1 diabetes. Diabetes Care. 29, 1744-9 (2006).

16. Lamos, E. M., Younk, L. M. \& Davis, S. N. Concentrated insulins: the new basal insulins. Therap Clin Risk Manag. 12, 389-400 (2016).

17. Hod, M. et al. A randomized trial comparing perinatal outcomes using insulin detemir or neutral protamine Hagedorn in type 1 diabetes. J Matern Fetal Neonatal Med. 27, 7-13 (2014).

18. Lv, S., Wang, J. \& Xu, Y. Safety of insulin analogs during pregnancy: a meta-analysis. Arch Gynecol Obstet. 292, 749-56 (2014).

19. Pantalone, K. M., Agarwal, S., Faiman, C. \& Glargine, V. S. NPH insulin therapy in pregnancies complicated by diabetes: an observational cohort study-comment on Negrato et al. Diabetes Res Clin Pract. 93, 9-10 (2011).

20. Padmanabhan, S., Jiang, S., McLean, M. \& Cheung, N. W. Effect of pregnancy on insulin requirements differs between type 1 and type 2 diabetes: A cohort study of 222 pregnancies. Aust N Z J Obstet Gynaecol. 56, 352-7 (2016).

21. De Jong, J. et al. Insulin analogues in pregnancy and specific congenital anomalies: a literature review. Diabetes Metab Res Rev 32, 366-75 (2016).

22. Mukhopaghyay, A., Farrell, T., Fraser, R. B. \& Ola, B. Continuous subcutaneous insulin infusion vs intensive conventional insulin therapy in pregnant diabetic women: a systematic review and methaanalysis of randomized, controlled trials. Am J Obstet Gynecol. 197, 447-56 (2007)

23. Giménez, M., Conget, I., Nicolau, J., Pericot, A. \& Levy, I. Outcome of pregnancy in women with type 1 diabetes intensively treated with continuous subcutaneous insulin infusion or conventional therapy. A case control study. Acta Diabetol. 44, 34-7 (2007).

24. Nathan, D. M., Lou, P. \& Avruch, J. Intensive conventional and insulin pump therapies in adult type I diabetes. A crossover study. Ann Intern Med. 97, 31-36 (1982).

25. González-Romero, S. Continuous subcutaneous insulin infusion versus multiple daily injections in pregnant women with type 1 diabetes. Diabetes Technol Ther. 12, 263-9 (2010).

26. Farrar, D., Tuffnell, D. J., West, J. \& West, H. M. Continuous subcutaneous insulin infusion versus multiple daily injections of insulin for pregnant women with diabetes. The Cochrane database of systematic reviews. 07, CD005542 (2016).

27. Wyatt, J. W. et al. Congenital anomaly rate in offspring of mothers with diabetes treated with insulin lispro during pregnancy. Diabetic Med. 22, 803-7 (2005).

28. Green, M. F. \& Bentley-lewis, M. D. Pregestational diabetes mellitus: Glycemic control during pregnancy. Uptodate (2019).

29. Jovanovic L. Prepregnancy couseling and evaluation of women with diabetes mellitus. Uptodate (2008).

\section{Author contributions}

L.T.C. and A.D.M. designed the study. J.B.J.L., R.R.M.M. and L.E.L. performed analysis of the data and prepared the manuscript. B.F. collected the obstetric data. L.T.C. and A.D.M. wrote the first draft of the manuscript and incorporated suggestions from all the co-authors.

\section{Competing interests}

The authors declare no competing interests.

\section{Additional information}

Correspondence and requests for materials should be addressed to C.L.-T.

Reprints and permissions information is available at www.nature.com/reprints.

Publisher's note Springer Nature remains neutral with regard to jurisdictional claims in published maps and institutional affiliations.

Open Access This article is licensed under a Creative Commons Attribution 4.0 International License, which permits use, sharing, adaptation, distribution and reproduction in any medium or format, as long as you give appropriate credit to the original author(s) and the source, provide a link to the Creative Commons license, and indicate if changes were made. The images or other third party material in this article are included in the article's Creative Commons license, unless indicated otherwise in a credit line to the material. If material is not included in the article's Creative Commons license and your intended use is not permitted by statutory regulation or exceeds the permitted use, you will need to obtain permission directly from the copyright holder. To view a copy of this license, visit http://creativecommons.org/licenses/by/4.0/.

(c) The Author(s) 2019 